\title{
Heterogeneity in Prescription Opioid Pain Reliever Misuse Across Age Groups: 2015-2017 National Survey on Drug Use and Health
}

\author{
Megan S. Schuler, Ph.D. ${ }^{1}$ (D, Andrew W. Dick, Ph.D. ${ }^{7}$, and Bradley D. Stein, M.D., Ph.D. ${ }^{2}$ \\ ${ }^{1}$ RAND Corporation, Boston, MA, USA; ${ }^{2}$ RAND Corporation, Pittsburgh, PA, USA.
}

BACKGROUND: Prescription opioid misuse among older adults has received little attention to date. Potential age variation in characteristics of and motivations for prescription opioid misuse has not been fully characterized yet has important implications for preventing diversion and misuse.

OBJECTIVE: To examine (1) age-specific patterns of source of misused prescription opioid pain relievers and motives for misuse and (2) age-specific and source-specific associations with opioid use disorder (OUD), heroin use, benzodiazepine misuse, and OUD treatment utilization.

DESIGN: Cross-sectional study using 3 waves (20152017) of the National Survey on Drug Use and Health (68\% average response rate)

PARTICIPANTS: Respondents aged 12 and older with pastyear prescription opioid pain reliever misuse $(n=8228)$

MAIN MEASURES: Source for the most-recently misused prescription pain reliever (categorized as medical, social, or illicit/other), motive for last episode of misuse, OUD, heroin use, benzodiazepine misuse, and OUD treatment. KEY RESULTS: Adults 50 and older comprised approximately $25 \%$ of all individuals reporting past-year prescription opioid misuse. A social source was most common for individuals under age 50 while a medical source was most common for individuals 50 and older. The most commonly reported motive for misuse was to "relieve physical pain"; the frequency of this response increased across age groups (47\% aged $12-17$ to $87 \%$ aged $65+$ ). Among adults age 50 and older with prescription opioid misuse, $17 \%$ met criteria for OUD, 15\% reported pastyear benzodiazepine misuse, and 3\% reported past-year heroin use.

CONCLUSIONS: Physicians continue to be a direct source of prescription opioids for misuse, particularly for older adults. Ongoing clinical initiatives regarding optimal opioid prescribing practices are needed in addition to effective non-opioid strategies for pain management. Clinical initiatives should also include screening adult and adolescent patients for non-medical use of prescription opioids as well as improving access to OUD treatment for individuals of all ages.

KEY WORDS: prescription pain reliever; opioid misuse; OUD treatment; diversion; medical source; age; heterogeneity.

Prior Presentations None.

Received April 30, 2019

Revised October 22, 2019

Accepted November 13, 2019

Published online December 2, 2019
J Gen Intern Med 35(3):792-9

DOI: $10.1007 / \mathrm{s} 11606-019-05559-6$

(c) Society of General Internal Medicine 2019

\section{INTRODUCTION}

An important contributor to the current U.S. opioid crisis is prescription opioid misuse, defined as use without a prescription, for reasons other than as directed, or in greater quantities, more frequently or longer than directed. ${ }^{1}$ Prescription opioids are diverted for misuse through multiple pathways including misuse of one's own medication prescribed for legitimate medical reasons, misuse of friends' or family members' legitimately prescribed opioids, or acquisition through the black market. ${ }^{2,3}$ Prescription opioid misuse is a strong risk factor for both opioid use disorder (OUD) ${ }^{4}$ and heroin use, ${ }^{5-7}$ which confer significantly heightened risk for fatal and non-fatal opioid overdose ${ }^{8-10}$ particularly given the growing presence of fentanyl and other synthetic opioids in the heroin supply. ${ }^{11}$

Prior research indicates that variation in the source of misused opioids may reflect heterogeneity in characteristics of prescription opioid misuse. ${ }^{12-14}$ Existing studies of national trends in source of diverted prescription opioids have largely focused exclusively on young adults, finding that the most common source for obtaining prescription opioids was from friends/relatives for free ${ }^{15-18}$ and that youth who reported purchasing prescription drugs had greater severity of misuse and concurrent substance use. ${ }^{15}$ While fewer studies have examined prescription opioid misuse among middle-age and older adults, emerging evidence points to important differences by age. Millennials have a higher risk of initiating heroin use after prescription opioid misuse than do Generation $\mathrm{X}$ or Baby Boomer individuals. ${ }^{19}$ A study using data from the 2009-2014 National Survey on Drug Use and Health (NSDUH) found that a medical source for misused opioids was more common among older adults than younger adults. ${ }^{14}$ Given that older adults are more likely to be co-prescribed opioids and benzodiazepines than younger adults ${ }^{20}$ and that benzodiazepine use elevates opioid overdose risk, ${ }^{21}$ older adults may experience heightened consequences from opioid misuse. While heroin accounts for more hospitalizations and deaths among younger adults, prescription opioids 
overwhelmingly account for hospitalizations and death among older adults. $^{20,22}$

The objective of this study is to further characterize the extent to which opioid misuse presents differently across age groups, particularly older adults. Using the 2015-2017 NSDUH data on individuals with past-year prescription opioid misuse, we examine how prescription opioid source (i.e., medical, social, and illicit/other) and motives for misuse vary across age groups. Furthermore, we investigate whether prevalence of OUD, heroin use, benzodiazepine misuse, and OUD treatment varies by age group or opioid source. Understanding how characteristics of prescription opioid misuse vary across age groups can inform policies designed to reduce diversion, misuse, and opioid-related mortality.

\section{METHODS}

\section{Data and Study Population}

Data were from the 2015-2017 NSDUH, an annual nationally representative survey of the civilian, non-institutionalized US population aged 12 and older. Data were collected using computer-assisted interviewing to facilitate accurate reporting of sensitive behaviors. The sample size for the public use NSDUH was 57,146 individuals in 2015 (70\% response rate), 56,897 individuals in 2016 (68\% response rate), and 56,276 individuals in 2017 (67\% response rate). All survey respondents gave informed consent and were compensated $\$ 30$.

Our sample was restricted to individuals aged 12 and older who reported past-year prescription opioid pain reliever misuse $(n=8758)$. Individuals who did not respond to the survey item assessing source of misused prescription pain relievers were excluded $(n=530)$, yielding a final sample of 8228 individuals. This study was deemed exempt from review by RAND's Institutional Review Board.

\section{Measures}

Prescription Opioid Pain Reliever Misuse. Individuals were first screened for any prescription opioid pain reliever use including OxyContin; of those who screen positive, pastyear misuse was defined as using prescription opioid pain relievers "in any way a doctor did not direct you to use it" during the past 12 months.

Source of Misused Prescription Opioids. Individuals were asked to identify the source for the prescription opioid pain relievers most-recently misused from eight mutually exclusive response options. We categorized responses into (1) medical source (i.e., "Got from one doctor" or "Got from more than one doctor"), (2) social source (i.e., "Got from friend or relative for free" or "Bought from friend or relative"), and (3) illicit/other source (i.e., "Bought from drug dealer," "Stole from doctor's office," "Took from friend or relative," or "Got some other way"). Similar classifications have been previously used, ${ }^{23}$ with the exception that we classified "took from friend or relative" as illicit/other rather than social, given that theft is involved.

Primary Motivation for Last Episode of Misuse. Individuals were asked "Which was the main reason you used prescription pain relievers the last time," with response choices including "relieve physical pain," "feel good/get high," "relax or relieve tension," "help with feelings or emotions," "hooked or have to have drug," "experiment/see what it's like," "help with sleep," "increase/decrease effects of other drug," and "some other reason."

Heroin Use. Lifetime and past-year heroin use were defined as any heroin use ever and in the past 12 months, respectively.

Opioid Use Disorder. Past-year OUD was defined as meeting DSM-IV abuse or dependence criteria with respect to either prescription pain relievers or heroin in the past 12 months.

Opioid Use Disorder Treatment. Individuals reporting lifetime drug treatment were asked which drug they sought treatment for at their "last or current" treatment episode. OUD treatment was defined as a last/current treatment episode for either heroin or prescription pain relievers.

Benzodiazepine Misuse. Past-year benzodiazepine misuse was defined as using benzodiazepines "in any way a doctor did not direct you to use it" during the past 12 months.

Age Groups. We classified individuals into five age groups: ages 12-17, ages 18-34, ages 35-49, ages 50-64, and ages 65 and older.

Demographics. Demographics were the following: gender (male, female), race/ethnicity (White, Black, Hispanic, Other), employment (full-time, part-time, student, unemployed, other), family income (less than $\$ 20,000 ; \$ 20,000-\$ 49,999$; $\$ 50,000-\$ 74,999 ; \$ 75,000+$ ), health insurance status (insured, uninsured), urbanicity (large metro area, small metro area, non-metro area), and year $(2015,2016,2017)$.

\section{Statistical Analysis}

Prevalence of demographic characteristics were estimated for the overall sample and by age group. Age-specific rates of source of misused prescription pain reliever and motives for last episode of misuse were calculated. Prevalence of OUD, heroin use, benzodiazepine misuse, and OUD treatment was estimated for the overall sample, as well as by age group and source. We examined five age groups (ages 12-17, 18-34, 35-49, 50-64, and 65+) when 
possible; in some analyses, the 50-64 and $65+$ groups were combined due to limited sample size.

Logistic regression was used to estimate the age-specific odds of source of misuse; three separate regression models were implemented (i.e., medical source vs. non-medical source; social source vs. non-social source; illicit/other source vs. non-illicit/other source). Due to the multiple comparisons across age groups, the Sidak correction was used for each model to control the type I error rate. ${ }^{24}$ Logistic regression was used to estimate the age-specific and source-specific odds of OUD, lifetime heroin use, past-year heroin use, benzodiazepine misuse, and OUD treatment. Five separate regression models were implemented, each of which simultaneously included indicators for age group and source; the Sidak correction was used to account for multiple comparisons across age and source groups. All regression models accounted for NSDUH survey design and adjusted for demographic characteristics. Analyses were conducted in Stata version 15.1.

\section{RESULTS}

\section{Sample Characteristics}

Of the 8228 individuals aged 12 and older who reported pastyear prescription pain reliever misuse, $7 \%$ were $12-17$ years old, $46 \%$ were $18-34$ years old, $24 \%$ were $35-49$ years old, $18 \%$ were $50-64$ years old, and 5\% were 65 and older after survey weighting (Table 1). Overall, $46 \%$ of individuals were female, $68 \%$ were non-Hispanic White, $16 \%$ were Hispanic, and $10 \%$ were non-Hispanic Black. The majority had health insurance (85\%), $49 \%$ were employed full-time, and $31 \%$ had a household income of $\$ 75,000$ or greater.

Relative to other age groups, adolescents were more likely to be female, less likely to be White, more likely to have a household income of $\$ 75,000$ or above, and more likely to have health insurance.

The relative age composition of individuals reporting misuse shifted across 2015-2017-in particular, the percentage of individuals $65+$ increased across survey years (30\% in 2015 to $41 \%$ in 2017).

\section{Age Group Differences in Source of Last Prescription Pain Reliever Misused}

A social source was the most common source for individuals aged 12-17 (reported by 49\%), aged 18-34 (56\%), and aged $35-49(48 \%)$, whereas a medical source was the most common for individuals aged 50-64 (52\%) and aged 65+ (63\%) (Fig. 1). The proportion of individuals reporting a medical source increased across age groups (26\% for ages $12-17 ; 63 \%$ for ages $65+)$, while the proportion of individuals reporting illicit/other source decreased (26\% for ages $12-17 ; 8 \%$ for ages $65+$ ).] $\rightarrow$

After adjusting for demographic characteristics, adolescents (relative to those aged 18-34) were significantly less likely to report a medical source (compared with a non-medical source)
$(\mathrm{aOR}=0.66,95 \% \mathrm{CI}=[0.49-0.88])$, whereas older individuals were significantly more likely to report a medical source (age 35-49, aOR $=1.72,95 \% \mathrm{CI}=[1.40-1.20]$; age 50-64, $\mathrm{aOR}=2.41,95 \% \mathrm{CI}=[1.71-3.27] ;$ age $65+, \mathrm{aOR}=3.96,95 \%$ $\mathrm{CI}=[2.20-7.10])$. Relative to individuals aged 18-34, older individuals were significantly less likely to report a social source (relative to a non-social source) (age 35-49, aOR = $0.76,95 \% \mathrm{CI}=[0.62-0.91]$; age $50-64, \mathrm{aOR}=0.63,95 \%$ $\mathrm{CI}=[0.47-0.86] ;$ age $65+, \mathrm{aOR}=0.39,95 \% \mathrm{CI}=[0.21-$ $0.74]$ ). No significant difference in the odds of reporting a social source was observed for adolescents compared with adults aged 18-34. Adolescents were significantly more likely to report an illicit/other source (relative to a non-illicit/other source) (age 12-17, aOR $=1.88,95 \% \mathrm{CI}=[1.43-2.49]$ ), whereas older individuals were significantly less likely (age $35-49, \mathrm{aOR}=0.66,95 \% \mathrm{CI}=[0.50-0.85]$; age $50+, \mathrm{aOR}=$ $0.41,95 \% \mathrm{CI}=[0.26-0.63])($ Table 2$)$.

\section{Age Group Differences in Motives for Last Episode of Misuse}

Across all age groups, the most common motive for last episode of misuse was to "relieve physical pain" (Table 3). The frequency of this response increased across age groups, ranging from $47 \%$ of adolescents to $87 \%$ of individuals aged 65 and older. Among younger age groups, the second most common motive was to "feel good/get high," reported by $20 \%$ of individuals aged $12-17,17 \%$ of individuals aged $18-34$, and $10 \%$ of individuals aged 35-49. Among older age groups, the second most common motive was to "relax or relieve tension," reported by $8 \%$ of those aged 50-64 and 6\% of those aged 65 and older. Adolescents were the most likely age group to report misuse as an "experiment/to see what it was like." Across age groups, few individuals reported misuse due to being "hooked/had to have drug" ( $<4 \%$ in every age group).

\section{Opioid Use Disorder, Heroin Use, Benzodiazepine Misuse, and OUD Treatment by Age and Opioid Source}

Prevalence of OUD, lifetime heroin use, past-year heroin use, past-year benzodiazepine misuse, and OUD treatment utilization varied by age group and source (Table 4). Regression results indicate that both age and source were significant predictors of OUD, heroin use, benzodiazepine misuse, and OUD treatment after adjusting for demographic characteristics (Table 5). Compared with a medical source, an illicit/other source was associated with elevated odds of OUD (aOR = $1.78,95 \% \mathrm{CI}=[1.36-2.32])$ whereas a social source was associated with reduced odds $(\mathrm{aOR}=0.73,95 \% \mathrm{CI}=[0.58-0.92])$.

Lifetime heroin use was significantly lower among adolescents $(\mathrm{aOR}=0.15,95 \% \mathrm{CI}=[0.08-0.27])$ relative to adults aged 18-34 and significantly elevated among those reporting an illicit/other source $(\mathrm{aOR}=3.34,95 \% \mathrm{CI}=[2.41-4.62])$ or social source $(\mathrm{aOR}=2.00,95 \% \mathrm{CI}=[1.48-2.71])$ relative to a medical source. Relative to adults aged 18-34, past-year 
Table 1 Demographic Characteristics of 2015-2017 NSDUH Respondents with Past-Year Prescription Opioid Misuse, Overall and by Age Group ( $n=8228)$

\begin{tabular}{|c|c|c|c|c|c|c|}
\hline & Overall (\%) & Age 12-17 (\%) & Age 18-34 (\%) & Age 35-49 (\%) & Age 50-64 (\%) & Age 65+ (\%) \\
\hline & $n=8228$ & $n=1297(6.8 \%)$ & $n=4785(45.8 \%)$ & $n=1533(24.2 \%)$ & $n=476(17.9 \%)$ & $n=137(5.2 \%)$ \\
\hline Female & 45.6 & 53.5 & 43.5 & 47.1 & 45.5 & 47.6 \\
\hline \multicolumn{7}{|l|}{ Race/ethnicity } \\
\hline White & 67.6 & 52.3 & 64.2 & 72.9 & 73.4 & 73.0 \\
\hline Black & 10.3 & 14.3 & 10.8 & 8.2 & 11.5 & 6.4 \\
\hline Hispanic & 16.1 & 25.2 & 17.8 & 14.0 & 10.2 & 18.0 \\
\hline Other & 6.0 & 8.2 & 7.1 & 4.8 & 4.9 & 2.6 \\
\hline \multicolumn{7}{|l|}{ Employment } \\
\hline Full-time & 48.8 & 5.0 & 53.6 & 60.0 & 48.2 & 14.0 \\
\hline Part-time & 15.4 & 22.0 & 17.8 & 13.5 & 10.5 & 11.7 \\
\hline Unemployed & 8.9 & 12.1 & 11.3 & 6.9 & 5.0 & 5.9 \\
\hline Other & 22.3 & 20.2 & 13.8 & 18.7 & 36.3 & 68.4 \\
\hline Student & 4.6 & 40.7 & 3.6 & 0.8 & 0.0 & 0.0 \\
\hline \multicolumn{7}{|l|}{ Household income } \\
\hline Less than $\$ 20,000$ & 21.8 & 16.7 & 24.6 & 17.6 & 21.3 & 25.4 \\
\hline$\$ 20,000-\$ 49,999$ & 31.4 & 31.4 & 34.3 & 28.0 & 28.5 & 31.4 \\
\hline$\$ 50,000-\$ 74,999$ & 15.5 & 12.6 & 14.9 & 16.7 & 16.4 & 14.7 \\
\hline$\$ 75,000$ or More & 31.3 & 39.3 & 26.1 & 37.8 & 33.8 & 28.4 \\
\hline Has health insurance & 85.1 & 94.4 & 79.9 & 85.2 & 90.1 & 100.0 \\
\hline \multicolumn{7}{|l|}{ Geographic region } \\
\hline Large metro & 55.5 & 54.8 & 54.0 & 56.7 & 58.1 & 55.3 \\
\hline Small metro & 30.8 & 30.8 & 32.1 & 30.7 & 28.7 & 27.7 \\
\hline Non-metro & 13.6 & 14.3 & 13.8 & 12.6 & 13.2 & 17.0 \\
\hline \multicolumn{7}{|l|}{ Year } \\
\hline 2015 & 35.9 & 38.1 & 36.7 & 35.7 & 35.0 & 29.4 \\
\hline 2016 & 33.2 & 34.4 & 32.8 & 32.0 & 36.4 & 30.2 \\
\hline 2017 & 30.9 & 27.5 & 30.4 & 32.2 & 28.6 & 40.5 \\
\hline
\end{tabular}

Prevalence estimates are weighted to account for NSDUH survey design

heroin use was significantly lower in all other age groups (age $12-17, \mathrm{aOR}=0.12,95 \% \mathrm{CI}=[0.06-0.24]$; age $35-49, \mathrm{aOR}=$ $0.66,95 \% \mathrm{CI}=[0.45-0.99] ;$ age $50+, \mathrm{aOR}=0.33,95 \% \mathrm{CI}=$ [0.16-0.70]); relative to a medical source, both an illicit/other source $(\mathrm{aOR}=5.21,95 \% \mathrm{CI}=[3.19-8.50])$ and a social source $(\mathrm{aOR}=2.15,95 \% \mathrm{CI}=[1.34-3.45])$ were associated with past-year heroin use. Past-year benzodiazepine misuse was significantly lower among older adults (age 35-49, aOR =
$0.57,95 \% \mathrm{CI}=[0.46-0.72]$; age $50+, \mathrm{aOR}=0.47,95 \% \mathrm{CI}=$ [0.34-0.66]) and significantly elevated among those reporting an illicit/other source $(\mathrm{aOR}=2.84,95 \% \mathrm{CI}=[2.19-3.68])$ or a social source $(\mathrm{aOR}=2.29,95 \% \mathrm{CI}=[1.86-2.82])$. Adolescents were significantly less likely to have received OUD treatment $(\mathrm{aOR}=0.53,95 \% \mathrm{CI}=[0.29-0.97])$ whereas those reporting an illicit/other source were significantly more likely $(\mathrm{aOR}=2.62,95 \% \mathrm{CI}=[1.72-4.01])$.

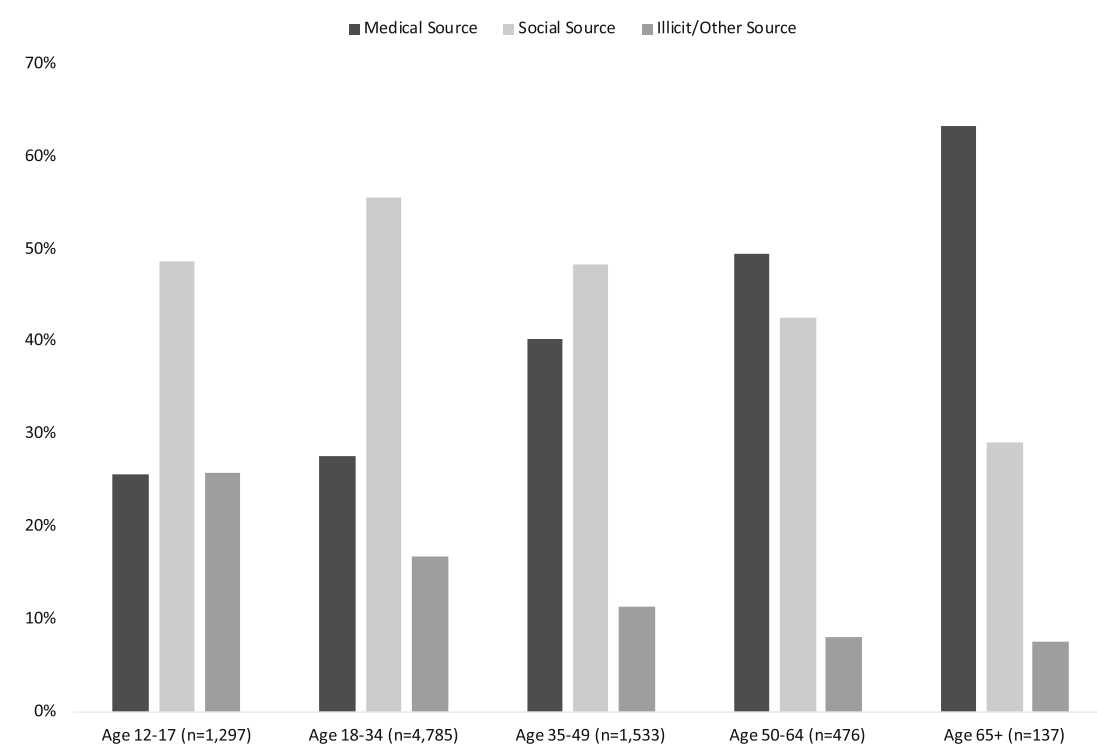

Fig. 1 Source of last prescription opioid pain reliever misused by age category among the 2015-2017 NSDUH respondents with past-year prescription opioid pain reliever misuse $(n=8228)$. Medical source is defined as "Got from one doctor" or "Got from more than one doctor." Social source is defined as "Got from friend or relative for free" or "Bought from friend or relative." Illicit/other source is defined as "Bought from drug dealer," "Stole from doctor's office," "Took from friend or relative," or "Got some other way." 
Table 2 Estimated Odds of Misused Prescription Opioid Source Among of 2015-2017 NSDUH Respondents with Past-Year Prescription Opioid Misuse $(n=8228)$

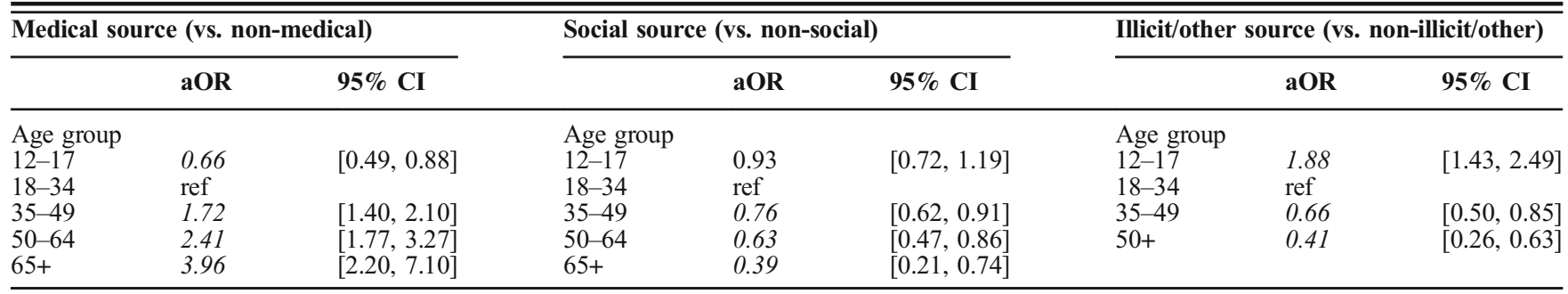

Italicized indicates statistical significance $(p<0.05)$. Estimates are from 3 different logistic regression models. All OR estimates are weighted to account for NSDUH survey design and adjusted for gender, racelethnicity, employment status, family income, health insurance status, urbanicity, and year. For illicit/other source, older adults are categorized as 50+ due to infrequency of response among adults ages 65+. For each outcome, 95\% CIs are estimated using the Sidak correction to account for multiple comparisons across age groups.

\section{DISCUSSION}

This study characterizes important variation across age groups with respect to source of misused prescription opioids as well as motives for misuse among a recent nationally representative sample. Our findings highlight that age group and source of misused opioids are both important predictors of OUD, heroin use, benzodiazepine misuse, and OUD treatment. While there has been increasing attention on fentanyl and other synthetic opioids due to recent increases in fentanyl-related overdose deaths, ${ }^{11,25}$ it is important to note that fentanyl overdoses are currently occurring in a relatively limited number of geographic areas ${ }^{26-29}$ while overdoses from prescription pain relievers remain prevalent in many regions of the country and are on the rise among older individuals. ${ }^{20,} 30,{ }^{31}$ Indeed, our finding highlights that prescription opioid misuse is an important public health issue among older adults: nearly $25 \%$ of all individuals reporting past-year prescription opioid misuse were aged 50 and older.

Table 3 Main Motivation for Last Episode of Prescription Opioid Misuse by Age Among 2015-2017 NSDUH Respondents with PastYear Prescription Opioid Misuse $(n=8228)$

\begin{tabular}{|c|c|c|c|c|c|}
\hline & $\begin{array}{l}\text { Age } \\
12-17 \\
(\%)\end{array}$ & $\begin{array}{l}\text { Age } \\
18-34 \\
(\%)\end{array}$ & $\begin{array}{l}\text { Age } \\
35-49 \\
(\%)\end{array}$ & $\begin{array}{l}\text { Age } \\
50-64 \\
(\%)\end{array}$ & $\begin{array}{l}\text { Age } \\
\mathbf{6 5 +} \\
(\%)\end{array}$ \\
\hline \multicolumn{6}{|c|}{ Main motivation for last episode of misuse } \\
\hline $\begin{array}{l}\text { Relieve physical } \\
\text { pain }\end{array}$ & 47.0 & 54.1 & 68.2 & 75.4 & 87.1 \\
\hline $\begin{array}{l}\text { Feel good/get } \\
\text { high }\end{array}$ & 19.6 & 17.3 & 10.3 & 5.0 & 0.2 \\
\hline $\begin{array}{l}\text { Relax or relieve } \\
\text { tension }\end{array}$ & 10.9 & 11.1 & 10.0 & 8.5 & 6.2 \\
\hline $\begin{array}{l}\text { Help with } \\
\text { feelings or } \\
\text { emotions }\end{array}$ & 7.5 & 4.0 & 2.8 & 2.4 & 1.6 \\
\hline $\begin{array}{l}\text { Hooked or have } \\
\text { to have drug }\end{array}$ & 0.1 & 3.4 & 2.6 & 1.3 & 0.0 \\
\hline $\begin{array}{l}\text { Experiment/see } \\
\text { what like }\end{array}$ & 8.9 & 4.0 & 0.4 & 1.4 & 1.1 \\
\hline Help with sleep & 3.5 & 4.0 & 3.7 & 5.4 & 2.7 \\
\hline $\begin{array}{l}\text { Increase/ } \\
\text { decrease effects } \\
\text { other drug }\end{array}$ & 0.8 & 1.0 & 0.7 & 0.4 & 1.0 \\
\hline $\begin{array}{l}\text { Some other } \\
\text { reason }\end{array}$ & 1.7 & 1.2 & 1.2 & 0.1 & 0.0 \\
\hline
\end{tabular}

Prevalence estimates are weighted to account for NSDUH survey design
While less attention has been focused on opioid misuse among older adults, misuse in this population may both have distinct etiology and be qualitatively different than misuse among younger individuals. ${ }^{32}$ We find that the rate of both reporting a medical source and misusing prescription opioids to "relieve physical pain" increased across age groups. Prescription opioid misuse among older adults may begin with the treatment of chronic pain or other health conditions, but prolonged use, even when clinically indicated, elevates the risk for physical dependence. ${ }^{33}$ Misuse may reflect opioidtolerant individuals trying to achieve the same pain control they previously achieved with lower doses, struggling with an opioid taper, or self-medicating for conditions commonly comorbid with chronic pain such as depression or anxiety. ${ }^{34}$, ${ }^{35}$ Efforts are needed to develop and disseminate safe and effective tapering protocols for individuals who have become (potentially inadvertently) physically dependent on opioid analgesics. Additionally, we found that $15 \%$ of older adults reported benzodiazepine misuse. Benzodiazepine misuse among older adults may arise from potentially inappropriate prescribing, namely overlapping opioid and benzodiazepine prescriptions, which may reflect poorly coordinated care across multiple providers. ${ }^{20}$ Concurrent use of benzodiazepines and opioids significantly increases overdose risk; ${ }^{21,36 \text {, }}$ ${ }^{37}$ this physiological risk is magnified by age such that older adults are particularly vulnerable. ${ }^{20,21,35}$

There is substantial concern about individuals progressing from opioid analgesic use and misuse to heroin, ${ }^{5-7}$ particularly when there is a disruption of the opioid analgesic supply. ${ }^{38,} 39$ Of individuals reporting past-year prescription opioid misuse, a minority met criteria for OUD or reported heroin use. Targeted prevention and intervention efforts are warranted to ensure that individuals comprising this sizeable, at-risk population of those with prescription opioid misuse do not develop more serious opioid-related problems. These efforts need to be inclusive of older adults, as this age group is often overlooked for prevention efforts. Furthermore, our findings indicate that rates of lifetime heroin use are double those of past-year heroin use among individuals with past-year prescription opioid misuse, highlighting that many individuals with lifetime heroin 
Table 4 Prevalence of Past-Year Opioid Use Disorder (OUD), Lifetime and Past-Year Heroin Use, Past-Year Benzodiazepine Misuse, and OUD Treatment by Age Group and Source Among of 2015-2017 NSDUH Respondents with Past-Year Prescription Opioid Misuse $(n=8228)$

\begin{tabular}{|c|c|c|c|c|c|c|c|c|c|c|}
\hline & \multicolumn{2}{|c|}{ Past-year OUD } & \multicolumn{2}{|c|}{$\begin{array}{l}\text { Lifetime heroin } \\
\text { use }\end{array}$} & \multicolumn{2}{|c|}{$\begin{array}{l}\text { Past-year } \\
\text { heroin use }\end{array}$} & \multicolumn{2}{|c|}{$\begin{array}{l}\text { Past-year } \\
\text { benzodiazepine } \\
\text { misuse }\end{array}$} & \multicolumn{2}{|c|}{$\begin{array}{l}\text { OUD } \\
\text { treatment }\end{array}$} \\
\hline & $N$ & $\%$ & $N$ & $\%$ & $N$ & $\%$ & $N$ & $\%$ & $N$ & $\%$ \\
\hline Overall & 1495 & 17.9 & 1097 & 13.4 & 487 & 5.2 & 2159 & 23.2 & 485 & 5.8 \\
\hline \multicolumn{11}{|l|}{ Age group } \\
\hline $12-17(n=1297)$ & 196 & 15.5 & 33 & 2.0 & 17 & 0.9 & 343 & 26.8 & 35 & 3.0 \\
\hline $18-34(n=4785)$ & 877 & 17.8 & 742 & 15.3 & 368 & 7.7 & 1421 & 29.5 & 320 & 6.8 \\
\hline $35-49(n=1533)$ & 313 & 19.7 & 243 & 14.6 & 85 & 4.7 & 299 & 18.3 & 103 & 6.5 \\
\hline $50+(n=613)$ & 109 & 17.2 & 79 & 11.9 & 17 & 2.6 & 96 & 14.7 & 27 & 4.0 \\
\hline \multicolumn{11}{|l|}{ Source } \\
\hline Medical $(n=2552)$ & 445 & 18.3 & 209 & 8.0 & 61 & 2.3 & 378 & 12.9 & 112 & 4.3 \\
\hline Social $(n=4248)$ & 648 & 14.4 & 575 & 14.8 & 246 & 5.4 & 1294 & 27.7 & 220 & 5.2 \\
\hline Illicit/other $(n=1428)$ & 402 & 29.9 & 313 & 23.0 & 180 & 13.1 & 487 & 33.5 & 153 & 11.8 \\
\hline
\end{tabular}

Prevalence estimates are weighted to account for NSDUH survey design

use continue to misuse opioid analgesics even after ceasing heroin use. While efforts to address heroin and fentanyl use are critical given the higher rates of associated mortality and medical comorbidity, $8,9,11,25$ this finding underscores the importance of continuing to address misuse of all types of opioids.

Study results indicate that source of misused prescription opioids was significantly associated with OUD, heroin use, and benzodiazepine misuse. Consistent with prior studies, individuals who reported an illicit/other source were significantly more likely to meet criteria for OUD than individuals reporting a social or medical source, ${ }^{12}$ additionally, an illicit/ other source was associated with both heroin use and benzodiazepine misuse. While those reporting an illicit/other source are at highest risk, we observed notable risk among those with a medical source, as $18 \%$ met criteria for OUD and $13 \%$ reported benzodiazepine misuse. As opioid misuse and opioid-related problems may go unrecognized in many clinical settings, there is ongoing need for clinician training regarding identifying individuals with opioid-related problems. ${ }^{40,41}$

While not every individual misusing opioids requires treatment, our findings that only $6 \%$ of individuals misusing opi- oids received treatment likely reflect unmet need. The observed lower rates of OUD treatment among individuals misusing opioids obtained from a medical or social source compared with an illicit/other source may reflect less severity, as well as potential under-recognition of misuse and opioidrelated problems among these individuals. ${ }^{40,41}$ The low rate of OUD treatment among adolescents is consistent with other studies documenting challenges in teens with opioid-related problems getting treatment, ${ }^{42-44}$ highlighting the need for ongoing efforts to increase available treatment options for younger individuals. Furthermore, OUD treatment rates were also low among older adults. To date, few studies have examined OUD treatment among older adults, but evidence suggests that older adults may have more successful treatment outcomes than younger adults, especially if seeking treatment for opioid misuse that arose later in life (rather than chronic opioid misuse). ${ }^{45}$

Several limitations deserve mention. As of 2015, the NSDUH asks respondents to identify the source of the last prescription opioids misused; the observed patterns in diversion source may not reflect modal diversion source if the reported source is not their most frequent/primary source.

Table 5 Estimated Odds of Past-Year Opioid Use Disorder (OUD), Lifetime and Past-Year Heroin Use, Past-Year Benzodiazepine Misuse, and OUD Treatment by Age Group and Source Among of 2015-2017 NSDUH Respondents with Past-Year Prescription Opioid Misuse ( $n=8228$ )

\begin{tabular}{|c|c|c|c|c|c|c|c|c|c|c|}
\hline & \multicolumn{2}{|c|}{ Past-year OUD } & \multicolumn{2}{|c|}{ Lifetime heroin use } & \multicolumn{2}{|c|}{ Past-year heroin use } & \multicolumn{2}{|c|}{$\begin{array}{l}\text { Past-year } \\
\text { benzodiazepine } \\
\text { misuse }\end{array}$} & \multicolumn{2}{|c|}{ OUD treatment } \\
\hline & OR & $95 \% \mathrm{CI}$ & OR & $95 \% \mathrm{CI}$ & OR & $95 \% \mathrm{CI}$ & OR & $95 \% \mathrm{CI}$ & OR & $95 \% \mathrm{CI}$ \\
\hline \multicolumn{11}{|l|}{ Age group } \\
\hline $12-17$ & 0.76 & {$[0.54,1.07]$} & 0.15 & {$[0.08,0.27]$} & 0.12 & {$[0.06,0.24]$} & 1.04 & {$[0.80,1.35]$} & 0.53 & {$[0.29,0.97]$} \\
\hline 18-34 & ref & & ref & & ref & & ref & & ref & \\
\hline $35-49$ & 1.21 & {$[0.96,1.52]$} & 1.09 & {$[0.84,1.42]$} & 0.66 & {$[0.45,0.99]$} & 0.57 & {$[0.46,0.72]$} & 1.03 & {$[0.71,1.49]$} \\
\hline $50+$ & 0.90 & {$[0.63,1.27]$} & 0.81 & {$[0.50,1.29]$} & 0.33 & {$[0.16,0.70]$} & 0.47 & {$[0.34,0.66]$} & 0.55 & {$[0.28,1.09]$} \\
\hline \multicolumn{11}{|l|}{ Source } \\
\hline Medical & ref & & ref & & ref & & ref & & ref & \\
\hline Social & 0.73 & {$[0.58,0.92]$} & 2.00 & {$[1.48,2.71]$} & 2.15 & {$[1.34,3.45]$} & 2.29 & {$[1.86,2.82]$} & 1.14 & {$[0.77,1.69]$} \\
\hline Illicit/other & 1.78 & {$[1.36,2.32]$} & 3.34 & {$[2.41,4.62]$} & 5.21 & {$[3.19,8.50]$} & 2.84 & {$[2.19,3.68]$} & 2.62 & {$[1.72,4.01]$} \\
\hline
\end{tabular}

Italicized indicates statistical significance $(p<0.05)$. Estimates are from 5 different logistic regression models, each of which simultaneously includes age group and source. All OR estimates are weighted to account for NSDUH survey design and adjusted for gender, racelethnicity, employment status, family income, health insurance status, urbanicity, and year. For each outcome, 95\% CIs are estimated using the Sidak correction to account for multiple comparisons across age groups and source groups, respectively 
The NSDUH lacks information regarding the specialty of the opioid prescriber, as well as measures of important contextual factors that may contribute to age-related differences in prescription opioid source, including chronic pain, social support, and life transitions among older adults. Given the crosssectional nature of the data, we strictly examined cooccurring use of prescription opioids and heroin; we cannot determine whether prescription opioid misuse preceded heroin use or vice versa.

\section{CONCLUSIONS}

Prescription opioid misuse remains a strong risk factor for heroin use and opioid use disorder, ${ }^{5,6,8}$ both of which are associated with a range of negative consequences beyond overdose (e.g., suicidality, hepatitis C, neonatal abstinence syndrome). ${ }^{46-48}$ Our results demonstrating heterogeneity in prescription opioid misuse characteristics across age groups highlight the need for a diverse range of clinical and policy responses. Continued efforts to ensure clinically thoughtful opioid prescribing (e.g., utilizing opioid alternatives; managing patients' expectations of pain, which may improve pain tolerance; prescribing minimally adequate doses of opioids) are imperative to decrease the amount of opioids available for misuse, yet caution is required to avoid under-treating pain. ${ }^{49}$ Consistent with expert recommendations,${ }^{50}$ initiatives should also include screening adult and adolescent patients for prescription opioid misuse as well as improving access to OUD treatment for individuals of all ages.

Corresponding Author: Megan S. Schuler, Ph.D.; RAND Corporation, Boston, MA, USA (e-mail: mschuler@rand.org).

Funding Information This work was funded by awards RO1 DAO45800 and P5O DA046351.

\section{Compliance with Ethical Standards:}

Conflict of Interest: The authors declare that they do not have a conflict of interest.

Disclaimer: The content is solely the responsibility of the authors and does not necessarily represent the official views of NIDA, the NIH, or the US Government.

Prior Presentations: None.

\section{REFERENCES}

1. Kolodny A, Courtwright DT, Hwang CS, et al. The prescription opioid and heroin crisis: a public health approach to an epidemic of addiction. Annu Rev Public Health. 2015;36:559-74.

2. Han B, Compton WM, Blanco C, Crane E, Lee J, Jones CM. Prescription opioid use, misuse, and use disorders in U.S. Adults: 2015 National Survey on Drug Use and Health. Ann Intern Med. 2017;167:293-301.

3. Hulme S, Bright $\mathbf{D}$, Nielsen $\mathbf{S}$. The source and diversion of pharmaceutical drugs for non-medical use: a systematic review and meta-analysis. Drug Alcohol Depend. 2018;186:242-56.
4. Elliott KR, Jones E. The association between frequency of opioid misuse and opioid use disorder among youth and adults in the United States. Drug Alcohol Depend. 2019;197:73-77.

5. Compton WM, Jones CM, Baldwin GT. Relationship between nonmedical prescription-opioid use and heroin use. N Engl J Med. 2016;374:154-63.

6. Cerda M, Santaella J, Marshall BD, Kim JH, Martins SS. Nonmedical prescription opioid use in childhood and early adolescence predicts transitions to heroin use in young adulthood: a national study. J Pediatr. 2015;167:605-12 e1-2.

7. Guarino H, Mateu-Gelabert P, Teubl J, Goodbody E. Young adults' opioid use trajectories: from nonmedical prescription opioid use to heroin, drug injection, drug treatment and overdose. Addict Behav. 2018;86:118-23.

8. Ciccarone D. The triple wave epidemic: supply and demand drivers of the US opioid overdose crisis. Int J Drug Policy. 2019:S09553959(19)30018-0.

9. Hedegaard H, Bastian BA, Trinidad JP, Spencer M, Warner M. Drugs most frequently involved in drug overdose deaths: United States, 20112016. Natl Vital Stat Rep. 2018;67:1-14.

10. CDC WONDER. Multiple cause of death 1999-2017. 2019.

11. Ciccarone D. Fentanyl in the US heroin supply: a rapidly changing risk environment. Int J Drug Policy. 2017;46:107-11.

12. Ford JA, Lacerenza C. The relationship between source of diversion and prescription drug misuse, abuse, and dependence. Subst Use Misuse. 2011;46:819-27.

13. Daniulaityte R, Falck R, Carlson RG. Sources of pharmaceutical opioids for non-medical use among young adults. J Psychoactive Drugs. 2014;46: 198-207.

14. Schepis TS, McCabe SE, Teter CJ. Sources of opioid medication for misuse in older adults: results from a nationally representative survey. Pain. 2018; 159:1543-49.

15. Schepis TS, Krishnan-Sarin S. Sources of prescriptions for misuse by adolescents: differences in sex, ethnicity, and severity of misuse in a population-based study. J Am Acad Child Adolesc Psychiatry. 2009;48:828-36.

16. Schepis TS, Wilens TE, McCabe SE. Prescription drug misuse: sources of controlled medications in adolescents. J Am Acad Child Adolesc Psychiatry. 2019;58:670-80 e4.

17. Hu MC, Griesler P, Wall M, Kandel DB. Age-related patterns in nonmedical prescription opioid use and disorder in the US population at ages 12-34 from 2002 to 2014. Drug Alcohol Depend. 2017;177:23743.

18. McCabe SE, Teter CJ, Boyd CJ, Wilens TE, Schepis TS. Sources of prescription medication misuse among young adults in the United States: the role of educational status. J Clin Psychiatry. 2018;79:17m11958.

19. Wall M, Cheslack-Postava K, Hu MC, Feng T, Griesler P, Kandel DB. Nonmedical prescription opioids and pathways of drug involvement in the US: generational differences. Drug Alcohol Depend. 2018;182:103-11.

20. Rose AJ, McBain R, Schuler MS, et al. Effect of age on opioid prescribing, overdose, and mortality in Massachusetts, 2011 to 2015. J Am Geriatr Soc. 2019;67:128-32.

21. Jones CM, McAninch JK. Emergency department visits and overdose deaths from combined use of opioids and benzodiazepines. Am J Prev Med. 2015;49:493-501.

22. McBain R, Rose AJ, LaRochelle MR. The U.S. Opioid epidemic: one disease, diverging tales. Prev Med. 2018;112:176-78.

23. Saloner B, Bachhuber M, Barry CL. Physicians as a source of medications for nonmedical use: comparison of opioid analgesic, stimulant, and sedative use in a national sample. Psychiatr Serv. 2017;68:5662.

24. Šidák ZK. Rectangular confidence regions for the means of multivariate normal distributions. Journal of the American Statistical Association. 1967;62:626-33.

25. Socias ME, Wood E. Epidemic of deaths from fentanyl overdose. BMJ. 2017;358:j4355.

26. Monnat SM. Factors associated with county-level differences in U.S. Drug-related mortality rates. Am J Prev Med. 2018;54:611-19.

27. Monnat SM, Peters DJ, Berg MT, Hochstetler A. Using census data to understand county-level differences in overall drug mortality and opioidrelated mortality by opioid type. Am J Public Health. 2019;109:1084-91.

28. Stewart K, Cao Y, Hsu MH, Artigiani E, Wish E. Geospatial analysis of drug poisoning deaths involving heroin in the USA, 2000-2014. J Urban Health. 2017;94:572-86. 
29. Unick GJ, Ciccarone D. US regional and demographic differences in prescription opioid and heroin-related overdose hospitalizations. Int $\mathrm{J}$ Drug Policy. 2017;46:112-19.

30. Carter MW, Yang BK, Davenport M, Kabel A. Increasing rates of opioid misuse among older adults visiting emergency departments. Innov Aging. 2019;3:igz002.

31. Huhn AS, Strain EC, Tompkins DA, Dunn KE. A hidden aspect of the US opioid crisis: rise in first-time treatment admissions for older adults with opioid use disorder. Drug Alcohol Depend. 2018;193:142-47.

32. Cochran G, Rosen D, McCarthy RM, Engel RJ. Risk factors for symptoms of prescription opioid misuse: do older adults differ from younger adult patients? Journal of Gerontological Social Work. 2017;60:443-57.

33. Chang YP. Factors associated with prescription opioid misuse in adults aged 50 or older. Nurs Outlook. 2018;66:112-20.

34. Fink DS, Hu RR, Cerda M, et al. Patterns of major depression and nonmedical use of prescription opioids in the United States. Drug Alcohol Depend. 2015; 153:258-64.

35. Han BH, Sherman SE, Palamar JJ. Prescription opioid misuse among middle-aged and older adults in the United States, 2015-2016. Prev Med. 2019;121:94-98.

36. Sun EC, Dixit A, Humphreys K, Darnall BD, Baker LC, Mackey S. Association between concurrent use of prescription opioids and benzodiazepines and overdose: retrospective analysis. BMJ. 2017;356:j760.

37. Hwang CS, Kang EM, Kornegay CJ, Staffa JA, Jones CM, MCAninch JK. Trends in the concomitant prescribing of opioids and benzodiazepines, 2002-2014. Am J Prev Med. 2016;51:151-60.

38. Alpert A, Powell D, Pacula RL. Supply-side drug policy in the presence of substitutes: evidence from the introduction of abuse-deterrent opioids. American Economic Journal-Economic Policy. 2018;10:1-35.

39. Evans WN, Lieber E, Power P. How the reformulation of oxycontin ignited the heroin epidemic. National Bureau of Economic Research. 2018;w24475.

40. Gordon AJ, Harding JD. From education to practice: addressing opioid misuse through health care provider training: a special issue of substance abuse journal. Subst Abus. 2017;38:119-21.

41. Oldfield BJ, Tetrault JM, Wilkins KM, Edelman EJ, Capurso NA. Opioid overdose prevention education for medical students: adopting harm reduction into mandatory clerkship curricula. Subst Abus. 2019:1-6.
42. Hadland SE, Bagley SM, Rodean $\mathbf{J}$, et al. Receipt of timely addiction treatment and association of early medication treatment with retention in care among youths with opioid use disorder. JAMA Pediatrics. 2018;172:1029-37.

43. Carney BL, Hadland SE, Bagley SM. Medication treatment of adolescent opioid use disorder in primary care. Pediatr Rev. 2018;39:43-45.

44. Bagley SM, Hadland SE, Carney BL, Saitz R. Addressing stigma in medication treatment of adolescents with opioid use disorder. J Addict Med. 2017;11:415-16.

45. Carew AM, Comiskey C. Treatment for opioid use and outcomes in older adults: a systematic literature review. Drug Alcohol Depend. 2018; 182:48-57.

46. Powell D, Alpert A, Pacula RL. A transitioning epidemic: how the opioid crisis is driving the rise in hepatitis c. Health Aff (Millwood). 2019;38:28794.

47. Samples H, Stuart EA, Olfson M. Opioid use and misuse and suicidal behaviors in a nationally representative sample of US adults. Am J Epidemiol. 2019;188:1245-53.

48. Reddy UM, Davis JM, Ren Z, Greene MF, Opioid Use in Pregnancy NAS, Childhood Outcomes Workshop Invited S. Opioid use in pregnancy, neonatal abstinence syndrome, and childhood outcomes: executive summary of a joint workshop by the eunice kennedy shriver national institute of child health and human development, American college of obstetricians and gynecologists, American academy of pediatrics, society for maternal-fetal medicine, centers for disease control and prevention, and the march of dimes foundation. Obstet Gynecol. 2017;130:10-28.

49. Dowell D, Haegerich TM, R C. CDC guideline for prescribing opioids for chronic pain - United States, 2016. MMWR Recomm Rep. 2016;65:149.

50. U.S. Preventive Services Task Force. Draft evidence review: illicit drug use, including nonmedical use of prescription drugs: screening. 2019.

Publisher's Note Springer Nature remains neutral with regard to jurisdictional claims in published maps and institutional affiliations. 